\title{
Extratos vegetais no controle da antracnose e na conservação da qualidade em frutos de mamoeiro
}

DEMARTELAERE, A.C.F. ${ }^{*}$; GUIMARÃES, G.H.C.'; SILVA, J.A.'; LUNA, R.G. ${ }^{1 ;}$ NASCIMENTO, L.C.1 Universidade Federal da Paraíba, Centro de Ciências Agrárias - Rodovia BR 079 - Km 12, CEP 58.397-000, Areia-PB. *Autor para correspondência: andrea_celina@hotmail.com

RESUMO: O presente trabalho teve como objetivo avaliar a ação antifúngica dos extratos de Allamanda blanchetti A.DC. e Momordica charantia L. no controle de Colletotrichum gloesporioides e qualidade pós-colheita em frutos de mamoeiro da cultivar Sunrise solo. Os experimentos foram conduzidos nos Laboratório de Fitopatologia e Laboratório de Produtos de Origem Animal, CCA-UFPB, Campus-II, Areia-PB. Os frutos foram colhidos no estádio 1 de maturação, em seguida, sanitizados com hipoclorito de sódio a $1 \%$ por três minutos e pulverizados com os extratos etanólicos de $A$. blanchetti e $M$. charantia nas concentrações: 0,10 , 100,500 e $1000 \mu \mathrm{g} \cdot \mathrm{mL}^{-1}$. Os frutos foram distribuídos em bandejas de polipropileno expandido em temperatura ambiente $\left(23 \pm 2{ }^{\circ} \mathrm{C}\right)$ e umidade relativa em torno de $70 \%$. Após doze dias de armazenamento, os frutos foram avaliados quanto à incidência natural de C. gloesporioides, severidade, atividade da enzima peroxidase, sólidos solúveis, acidez titulável, relação SS/AT, perda de massa e aparência externa dos frutos. Foi realizada análise de regressão polinomial testando modelos até o terceiro grau para as concentrações dos extratos utilizando análise de variância pelo teste $F$ enquanto as médias foram comparadas pelo teste de Tukey a $5 \%$ de probabilidade, através do programa SAS ${ }^{\circledR}$ 9.2. Não se observou diferença estatística quando avaliou-se a incidência natural de $C$. gloesporioides em frutos de mamoeiro utilizando os extratos de $A$. blanchetti e $M$. charantia. Já na avaliação da severidade da antracnose, verificou-se diferença para o tratamento com o extrato de $A$. blanchetti, que apresentou as menores escalas de notas em relação ao tratamento com a $M$. charantia. Observou-se atividade da peroxidase (POD) em frutos de mamoeiro nos extratos de $A$. blanchetti e $M$. charantia. Os frutos tratados com $A$. blanchetti apresentaram teor de acidez, com máximo de $0,12 \mathrm{~g}$ de ácido cítrico. $100 \mathrm{~g}^{-1}$ e no de $M$. charantia apresentou aumento para $0,15 \mathrm{~g}$ de ácido cítrico.100 $\mathrm{g}^{-1}$. A relação SS/ AT diminuiu com o aumento das concentrações dos dois extratos. Os frutos tratados com $A$. blanchetti apresentaram maior perda de massa durante todo o armazenamento, sendo maior que $10 \%$ aos nove dias. Já a perda de massa dos frutos tratados com M. charantia apresentou comportamento linear, sendo superior a $12 \%$ aos 12 dias de armazenamento. A cor evoluiu de 1 (verde) para 6 (casca alaranjada) e a aparência dos frutos diminuiu com o decorrer do tempo de 5 (excelente) para 3 (regular) em todas concentrações dos extratos de $A$. blanchetti e $M$. charantia. Os extratos de $A$. blanchetti e $M$. charantia não reduziram a incidência natural, porém, só o extrato de $A$. blanchetti foi responsável por reduzir a severidade da antracnose. Ocorreu a atividade da enzima peroxidase em todos os tratamentos avaliados e conservaram a qualidade pós-colheita em frutos até os nove dias de armazenamento.

Palavras-chaves: Allamanda blanchetti, Momordica charanthia, Colletotrichum gloesporioides, Carica papaya L.

\begin{abstract}
Plant extracts in controlling anthracnose and quality conservation in papayas fruit. This study aimed to evaluate the antifungal effect of the extracts Allamanda blanchetti A.DC. and Momordica charantia L. in the control of Colletotrichum gloesporioides in papaya fruits of the Sunrise Solo cultivation, as well as their post-harvest quality. The trials were conducted in the Laboratory of Plant Pathology and Animal Products Laboratory, CCA-UFPB, Campus II, Areia-PB. The fruits were harvested at maturity stage 1, then sanitized with sodium hypochlorite $1 \%$ for three minutes and sprayed with ethanol extracts of $A$. blanchetti and $M$. charantia at concentrations of $0,10,100,500$ and $1000 \mu \mathrm{g} \cdot \mathrm{mL}^{-1}$. The fruits were distributed in
\end{abstract}

Recebido para publicação em 07/11/2014

Aceito para publicação em 17/04/2015

10.1590/1983-084X/14_147

Rev. Bras. PI. Med., Campinas, v.17, n.4, supl. III, p.1041-1048, 2015. 
polypropylene trays expanded at room temperature $\left(23 \pm 2{ }^{\circ} \mathrm{C}\right)$ and relative humidity around $70 \%$. After twelve days of storage, the fruits were evaluated for natural incidence of $C$. gloesporioides, severity, peroxidase enzyme activity, soluble solids, titratable acidity, SS/TA ratio, weight loss and external appearance of the fruit. Polynomial regression testing models to the third degree were employed for the extracts of concentrations, using analysis of variance by $F$ test. The averages were compared by Tukey test at $5 \%$ probability, through the SAS ${ }^{\oplus} 9.2$ program. There was no statistical difference observed when we evaluated the natural incidence of $C$. gloesporioides in the papaya fruit, using extracts from $A$. blanchetti and $M$. charantia. In the assessment of the severity of the anthracnose, there was no statistical difference for the treatment with the extract of $A$. blanchetti, which had smaller scales of notes when compared with the treatment using the $M$. charantia. It was observed peroxidase activity (POD) in the papaya fruits treated with the extracts of $A$. blanchetti and $M$. charantia. The fruits treated with $A$. blanchetti presented a maximum dose of acidity of $0.12 \mathrm{~g} \mathrm{~g}^{-1}$ of citric acid. $100 \mathrm{~g} \mathrm{~g}^{-1}$. In the fruits treated with $M$. charantia this increase was of $0.15 \mathrm{~g}$ of citric acid. $100 \mathrm{~g}^{-1}$. The SS/TA ratio decreased with increasing concentrations of the two extracts. The fruits treated with $A$. blanchetti presented higher weight loss of approximately $10 \%$, since the $M$. charantia was over $12 \%$. The color evolved from 1 (green) to 6 (Orange Peel) and the appearance of the fruit got worse according to the time, from 5 (excellent) to 3 (regular) in all the concentrations of the extracts of $A$. blanchetti and $M$. charantia. The $A$. blanchetti and $M$. charantia extracts did not reduce the natural incidence, however, only the $A$. blanchetti extract was able to decrease the severity of the anthracnose. The peroxidase enzyme presented activity in all treatments and kept the postharvest quality of the fruits in the nine days of storage.

\section{Keywords: Allamanda blanchetti, Carica papaya L., Colletotrichum gloesporioides, Momordica} charanthia

\section{INTRODUÇÃO}

O mamoeiro (Carica papaya L.) é uma espécie de grande importância econômica, e social, sendo apreciada e cultivada em quase todos os países da América tropical Paixão et al. (2012). No Brasil, destacam-se os estados do Espírito Santo com liderança na produção em torno de 931 toneladas, seguido do Rio Grande do Norte com 823 toneladas, Bahia 434 toneladas e o Ceará com 318 toneladas IBGE (2015).

Devido à alta produtividade aliada ao manejo inadequado, tem-se elevado o número de doenças pós-colheita em diversas espécies frutíferas (Serrano \& Cattaneo, 2010), como a antracnose que tem o agente causal Colletotrichum gloesporioides (Penz.) Penz. e Sacc responsável por ocasionar infecções em diferentes partes da planta. Nos frutos, podem ocorrer e permanecer quiescente até a pós-colheita e a medida que amadurece surgem manchas vermelho-arroxeadas, já visíveis com 48 horas após o início da infecção, evoluindo para manchas necróticas, reduzindo a qualidade dos frutos e ampliando as perdas em até $50 \%$ na produção Moura et al. (2013).

Algumas espécies de plantas como A Allamanda blanchetti A.DC. produzem compostos tóxicos que rompem o ciclo de vida de diversos microrganismos Arnason et al. (1989). Essas substâncias, como os iridóides, flavonóides, cumarinas e terpenóides são denominadas compostos secundários ou aleloquímicos, com importante papel ecológico na defesa química contra patógenos, insetos e predadores Guirado et al. (2004). A maioria desses metabólitos pode ser obtida de várias partes de plantas através de destilação, extração com solventes ou aquosos consistindo em técnicas com emprego de extratos vegetais, aminoácidos, microrganismos e óleos essenciais, enquadrando-se em estratégias com alto potencial no controle alternativo de doenças Huan et al. (2012).

A espécie Momordica charantia L., popularmente conhecida como melão-são-caetano, espécie pantropical, bastante utilizada no controle de doenças, devido à produção de substâncias bioativas como a momordicina, alcalóide, flavonóide, saponinas, glicosídeos, constituintes fenólicos, fenilalanina, arginina, lignano-calceolariosideo, triterpenos-momordicinase alcalóide zeatina, presentes na estrutura química dos mesmos, podendo ter efeito inibitório sobre a ação de diversos fungos Martins-Ramos et al. (2010).

A intensificação de estudos e pesquisas no controle de doenças pós-colheita tem dado ênfase à utilização de extratos de plantas medicinais que podem induzir a produção de diversas enzimas como a peroxidase, polifenoloxidase e a fenilalanina amônia-liase que estimulam a produção de metabólitos secundários responsáveis

Rev. Bras. PI. Med., Campinas, v.17, n.4, supl. III, p.1041-1048, 2015. 
pela formação de diferentes compostos fenólicos com ação fungitóxica (mecanismo direto) sendo responsáveis pela defesa no controle de diversos patógenos Bonett et al. (2012).

Diante desta perspectiva, o trabalho teve como objetivo avaliar a ação antifúngica dos extratos de alamanda e melão-são-caetano no controle antracnose e qualidade pós-colheita em frutos de mamoeiro.

\section{MATERIAL E MÉTODOS}

O experimento para avaliação da incidência, severidade e as análises bioquímicas foram realizadas no Laboratório de Fitopatologia e a análise enzimática foi conduzida no Laboratório de Análises de Produtos de Origem Animal, pertencentes ao Centro de Ciências Agrárias-UFPB, Campus-II, Areia-PB.

Os extratos vegetais utilizados foram obtidos a partir de folhas de allamanda e melãosão-caetano coletadas na Área Experimental da Chã de Jardim do CCA (Latitude: 6 57' 42" Sul, Longitude: $35^{\circ} 41^{\prime} 43^{\prime \prime}$ Oeste), posteriormente foram feitas as exsicatas e tombadas com os seguintes códigos: 21.981 (allamanda) e 21.982 (melão-sãocaetano) no Herbário Jayme Coelho de Morais, pertencente ao CCA, Campus II, Areia-PB, em seguida, dispostas em sacos de papel e levadas à estufa com temperatura constante de $60^{\circ} \mathrm{C}$ por um período de $72 \mathrm{~h}$, até a obtenção da matéria seca. Posteriormente, as folhas foram trituradas (pó) em moinho de facas, pesadas $100 \mathrm{~g}$ e colocadas em recipientes de vidro em temperatura ambiente $\left(23 \pm 2^{\circ} \mathrm{C}\right) \mathrm{com}$ adição de $200 \mathrm{~mL}$ de etanol $(96 \%)$, agitadas duas vezes ao dia, por um período de 72 horas em infusão Carrera et al. (2014).

Por meio de evaporador rotativo, foi extraído à frio o concentrado e levados à estufa de circulação forçada por um período de uma hora, até atingir uma consistência pastosa do extrato bruto. Posteriormente, foi feita a diluição do extrato em água destilada esterilizada (ADE) com ajuda de um agitador magnético, por um período de duas horas para obtenção das concentrações dos extratos de $0,10,100,500$ e $1000 \mu \mathrm{g} \cdot \mathrm{mL}^{-1}$.

Os frutos de mamoeiro da cultivar Sunrise solo, foram colhidos no estádio 1 de maturação (até $10 \%$ da área superficial da casca com coloração amarela) e selecionados com padrões uniformes de peso médio em torno de $500 \mathrm{~g}$, com a forma periforme ou oval, casca lisa, frutos firmes, com polpa espessa, de coloração vermelho-alaranjada, cavidade interna e estrelada CEAGESP (2015), adquiridos em estabelecimento comercial, oriundos de produtores do município de Areia-PB.

Em seguida, sanitizados com hipoclorito de sódio a $1 \%$ por três minutos. Após secagem, foram pulverizados com os extratos etanólicos de $A$. blanchetti e $M$. charantia e distribuídos em bandejas de polipropileno expandido, armazenados durante doze dias à temperatura ambiente $\left(23 \pm 2^{\circ} \mathrm{C}\right)$, umidade relativa em torno de $70 \%$ e avaliados quanto à incidência natural de C. gloesporioides, através de observação visual e auxílio de microscópio estereoscópico Menezes (2006) e os resultados expressos em percentagem de frutos com sinais de antracnose, com base em Sangoi et al. (2000), utilizando a seguinte fórmula:

$$
\text { Incidência }(\%)=\frac{(\text { Frutos infectados } * 100)}{\text { Total de frutos }}
$$

Foi feita a avaliação severidade da doença, através da escala de notas onde $1=$ Sem sintomas visíveis de podridão peduncular; 2 = Presença de pequenas pontuações (até $3 \mathrm{~mm}$ ) aquosas superficiais na região do pedúnculo; 3 = Presença de lesões aquosas ou mumificadas, não coalescentes, mais acentuadas abrangendo maior região em torno do pedúnculo; 4 = Presença de lesões aquosas ou mumificadas, não coalescentes, mais acentuadas abrangendo maior região em torno do pedúnculo e 5 = Lesões como aquelas descritas no item anterior, abrangendo maior região, descendo pela polpa do fruto, podendo chegar até a cavidade das sementes e o tecido dessa região pode apresentar excessivo amaciamento Nery-Silva et al. (2001).

Para a atividade da Peroxidase (POD) foi foram retirados 3 frutos de cada repetição e e no primeiro dia e aos 12 dias do experimento, foi determinada da reação que consistiu a adição de $750 \mu \mathrm{L}$ do tampão de reação (tampão fosfato de sódio $(100 \mathrm{mM})(\mathrm{pH} \mathrm{6,0)}, 250 \mu \mathrm{L}$ de guaiacol (1,7\%), $250 \mu \mathrm{L}\left(\mathrm{H}_{2} \mathrm{O}_{2}\right)$ e $250 \mu \mathrm{L}$ composto por: 150 $\mu \mathrm{L}$ de água $+100 \mu \mathrm{L}$ do extrato, onde o guaiacol peroxidase converteu o guaiacol em tetraguaiacol. A reação foi paralisada com a adição de $800 \mu \mathrm{L}$ de ácido perclórico $(2,0 \mathrm{M})$ e monitorada a por um período de dois min e, a cada 15 segundos foram realizadas leituras para verificar a atividade da enzima peroxidase com comprimento de onda de $470 \mathrm{~nm}$ e expressa em U.A./min./mg de proteína (Roncato \& Pascholati, 1998).

O teor de sólidos solúveis (SS) foi obtido através do suco extraído de fatias de frutos cortadas longitudinalmente e determinado em refratômetro digital, com correção automática de temperatura, sendo os resultados expressos em porcentagem AOAC (2002). A acidez titulável (AT) foi determinada por titulometria com hidróxido de sódio $0,1 \mathrm{~N}$, IAL (2008) e expresso em porcentagem de ácido cítrico.100 g-1 de suco. A relação SS/AT (Sólidos Solúveis/Acidez Titulável) foi obtida pela divisão

Rev. Bras. PI. Med., Campinas, v.17, n.4, supl. III, p.1041-1048, 2015. 
simples dos valores para SS pelos valores obtidos para AT. A perda de massa foi realizada diariamente pesando as bandejas em balança semi analítica, tomando-se como base a massa inicial.

Aparência externa dos frutos foi avaliada segundo Rocha et al. (2005), através de escala subjetiva de notas ( 1 = Inaceitável, extremamente deteriorado, perda completa da turgidez e brilho, superfície murcha; 2 = Ruim, severamente deteriorado, murchamento acentuado, superfície murcha em quase $50 \%$ do fruto, sem brilho aparente e perda total do aroma, presenças de manchas; 3 = Regular, média deterioração, pouco frescor, ligeira perda da turgidez, perda de brilho, aparência ligeiramente atrativa; 4 = Bom, leve deterioração, produto fresco, túrgido, superfície apresentando brilho pouco intenso e brilhante e 5 = Excelente, ausência de deterioração, produto fresco, túrgido, superfície lisa e brilhante, atrativo).

Os frutos com notas iguais ou inferiores a 3 foram considerados impróprios para o consumo. A análise de aparência foi realizada a cada três dias, por um grupo de oito avaliadores treinados, pertencentes à equipe do laboratório. A coloração da casca foi estabelecida de acordo com a escala de notas subjetiva proposta por Wills \& Widjanarko (1995).

O delineamento experimental foi inteiramente casualizado, com 10 tratamentos: T-1 Extrato de alamanda $10 \mu \mathrm{g} \cdot \mathrm{mL}^{-1}$, T-2 Extrato de alamanda $100 \mu \mathrm{g} \cdot \mathrm{mL}^{-1}$, T-3 Extrato de alamanda $500 \mu \mathrm{g} \cdot \mathrm{mL}^{-1}, \mathrm{~T}-4$ Extrato de alamanda $1000 \mu \mathrm{g} \cdot \mathrm{mL}^{-1}$, T-5 Extrato de melão-são-caetano $10 \mu \mathrm{g} \cdot \mathrm{mL}^{-1}$, T-6 Extrato de melão-são-caetano $100 \mu \mathrm{g} \cdot \mathrm{mL}^{-1}$, T-7 Extrato de melão-são-caetano $500 \mu \mathrm{g} \cdot \mathrm{mL}^{-1}, \mathrm{~T}-8$ Extrato de melão-são-caetano $1000 \mu \mathrm{g} \cdot \mathrm{mL}^{-1}, \mathrm{~T}-9$ testemunha (ADE) e T-10 fungicida (Prochloraz, 450 $\mathrm{g} / \mathrm{L}$ ) e cinco repetições com cinco frutos, totalizando 250 frutos. Foi realizada análise de regressão polinomial testando modelos até o terceiro grau para as concentrações dos extratos utilizando a análise de variância pelo teste $\mathrm{F}$ e as médias foram comparadas pelo teste de Tukey a $5 \%$ de probabilidade, através do programa SAS ${ }^{\circledR} 9.2$.

\section{RESULTADOS E DISCUSSÕES}

Não observou-se diferença estatística quando avaliou-se a incidência de C. gloesporiodes aplicando os extratos de $A$. blanchetti e $M$. charantia, em frutos de mamoeiro, apresentando médias $(2,75 ; 2,25 ; 2,0 ; 0,25$ e 2,$85 ; 2,5 ; 2,0$; $0,4 \%$ ) respectivamente. Pórem, quando avaliou-se a severidade da antracnose, verificou diferença estatística, para o tratamento com o extrato de $A$. blanchetti, apresentando as menores escalas de notas e demonstrando eficienciencia na redução da severidade em relação ao tratamento utilizando a $M$. charantia em frutos de mamoeiro durante os doze dias de avaliação (Figura 1).

Comportamento semelhante ao presente trabalho foi verificado por Leite et al. (2009) quando observaram redução da severidade em maçã (Malus domestica Borkh) no controle da antracnose causada por C. gloesporioides, em função das concentrações crescentes do óleo de nim (Azadirachta indica A. Juss). SiqueiraJunior et al. (2011) avaliando extratos etanólicos de sementes de pitomba (Talisia esculenta) e de folhas de tanchagem (Plantago major) verificaram que as diferentes espécies apresentaram potencial fungicida contra o C. gloeosporioides no controle da antracnose em frutos de mamoeiro.

A utilização do extrato de $A$. blanchetti abre uma nova perspectiva no manejo alternativo no controle de doenças, pois, essa espécie constitui uma fonte de substâncias biologicamente ativas Martins-Ramos et al. (2010) que pode ter sido responsável por reduzir a severidade da antracnose em frutos de mamoeiro. Já a $M$. charanthia, apesar de apresentar diversas substâncias químicas em sua composição, não foi capaz de diminuir a severidade da antracnose até os doze dias de avaliação.

Avaliando a atividade da peroxidase (POD) em frutos de mamoeiro, utilizando os extratos de $A$. blanchetti e M. charantia, não observou-se diferença estatística, apresentando médias: $(139,82 ; 107,28$; 179,24; 99,34 e 130,95; 155,20; 125,16; 152,18 U.A. $\mathrm{mg} /$ proteína/min).

Comportamento semelhante ao presente trabalho foi verificado por Tavares et al. (2009) quando avaliaram à atividade de peroxidase utilizando os indutores de resistência bióticos e abióticos como o fosfito de potássio $(2,5$ e $5 \mathrm{~mL}$

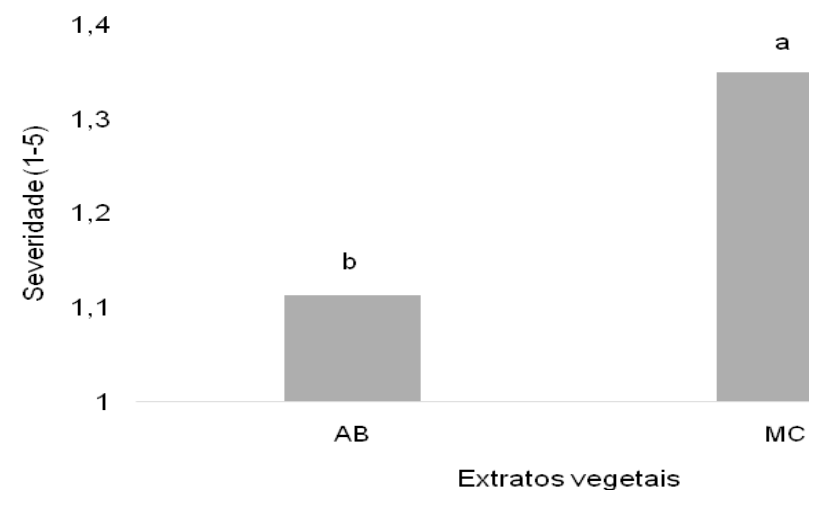

FIGURA 1. Escala de notas da severidade da antracnose descrita por Nery-Silva et al. (2001), em frutos de Carica papaya da cultivar Sunrise solo, tratados com as concentrações 0; 10; 100; 500 e 1000 ( $\mu \mathrm{g} \cdot \mathrm{mL}^{-1}$ ) dos extratos de Allamanda blanchetti (AB) e Momordica charantia (MC) durante 12 dias de armazenamento. 
$\mathrm{L}^{-1}$ ), ácido salicílico 0,15 e 0,30\%, Reforce (indutor comercial) + ácido salicílico a 5\%, acibenzolar-S-metil (ASM) $\left(0,15\right.$ e $\left.0,30 \mathrm{~g} \mathrm{~L}^{-1}\right)$ e com o indutor biótico Saccharomyces cerevisiae (3 e $6 \mathrm{~mL} \mathrm{L-1}$ ) na redução da podridão radicular em mamoeiro causada por Phytophthora palmivora (Butl.) Butl, verificaram que os tratamentos não diferiram estatisticamente em relação à atividade desta enzima.

Cavalcanti et al. (2006) constataram que a atividade da peroxidase pode ser um indicativo na ativação de respostas de defesa, a partir da aplicação do eliciador. Pois, a atividade desta enzima no presente trabalho, pode ser explicada através da potencialização da ligação de proteínas com radicais fenilpropanóides, produzindo substancias tóxicas e atuando diretamente sobre os patógenos, influenciando na redução da severidade da doença, reforçando a ligação entre os polissacarídeos da parede celular dos frutos, produzindo suberinas, lignificando os tecidos e podendo também inibir o amadurecimentos de frutos, ampliando a vida útil na pós-colheita Lurie et al. (1997)

Verificou-se que não houve diferença significativa entre os tratamentos utilizando os extratos de $M$. charantia e A. blanchetti quanto ao teor de sólidos solúveis, acidez titulável e relação sólidos solúveis/acidez titulável (Figuras 2 e 3).
Carnelossi et al. (2009) estudando óleos essenciais para o controle de C. gloesporioides em frutos de mamão, relata teores de sólidos solúveis variando de 10,1 a $12,1 \%$. Esse teor é uma medida indireta do teor de açúcares, uma vez que aumenta à medida que esses teores vão se acumulando na fruta, não representando o teor exato dos açúcares Silva et al. (2012), sendo um dos principais responsáveis pelo sabor e principal influenciando na aceitação de frutos Mascarenhas et al. (2010).

Para frutos de mamoeiro, a acidez é muito baixa, o que faz com que a relação sólidos solúveis/ acidez titulável (SS/AT) seja elevada. Nos frutos tratados com os extratos de $M$. charantia e $A$. blanchetti a relação SS/AT diminuiu com o aumento das concentrações (Figuras-2 e 3). A acidez é um dos principais componentes do sabor, no entanto a aceitação geral do fruto depende do balanço entre ácidos e açúcares Mascarenhas et al. (2010).

A relação sólidos solúveis e acidez titulável em mamão variam de 68 a 202 dependendo do cultivar Santana et al. (2004). A relação SS/AT é utilizada para avaliar o grau de maturação e, portanto, o sabor da maioria dos frutos e quando avaliada pode auxiliar na compreensão dos processos metabólicos em progresso, podendo também indicar mudança nos processos metabólicos dos frutos.
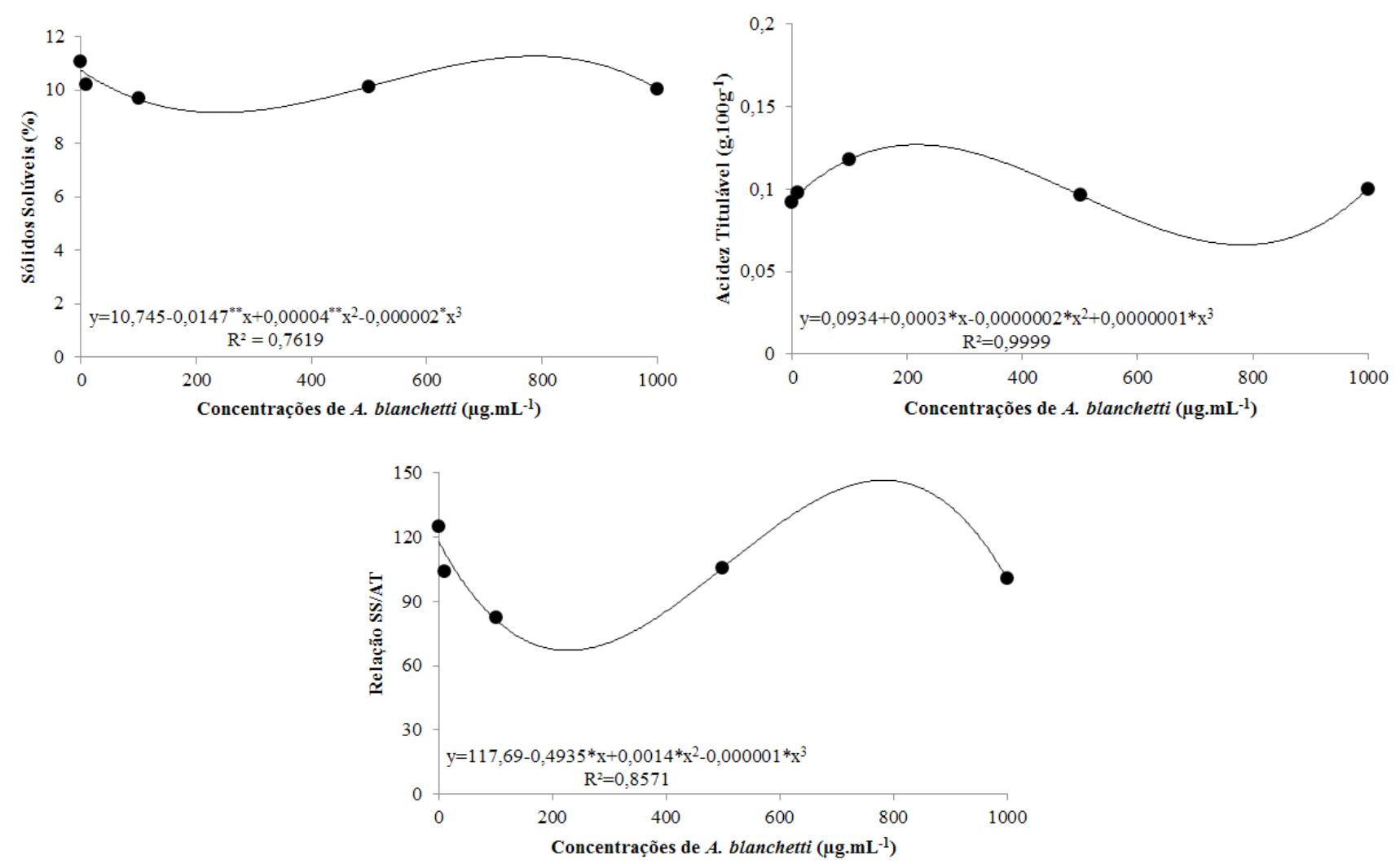

FIGURAS 2. Sólidos solúveis (\%), acidez titulável (g.100 g-1), relação sólidos solúveis/acidez titulável em frutos de Carica papaya da cultivar Sunrise solo, tratados com diferentes concentrações do extrato de Allamanda blanchetti durante 12 dias de armazenamento. 

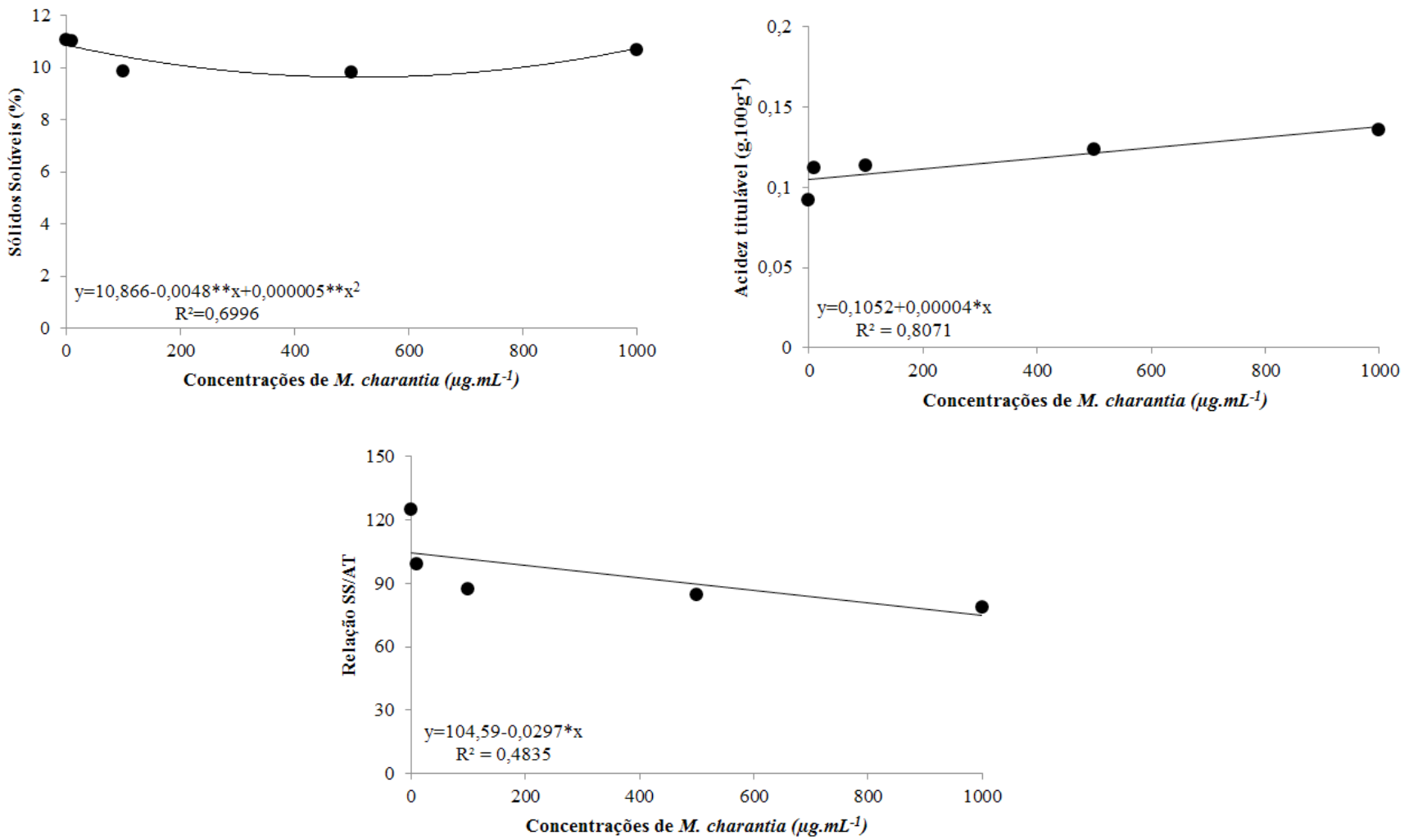

FIGURAS 3. Sólidos solúveis (\%), acidez titulável ( $\left.\mathrm{g} .100 \mathrm{~g}^{-1}\right)$, relação sólidos solúveis/acidez titulável e potencial hidrogenionico $(\mathrm{pH})$ em frutos de Carica papaya da cultivar Sunrise solo, tratados com diferentes concentrações do extrato de Momordica charantia durante 12 dias de armazenamento.

Os frutos tratados com $A$. blanchetti apresentaram maior perda de massa durante todo o armazenamento, sendo maior que $10 \%$ aos nove dias. Já a perda de massa dos frutos tratados com $M$. charantia apresentou comportamento linear, sendo superior a $12 \%$ aos 12 dias de armazenamento (Figuras 4).

O limite crítico de perda de massa, considerado por diversos autores é 10\% e acima desse nível as perdas podem influenciar em características visuais, como a aparência. A perda de massa dos frutos pode ser ocasionada pela perda de turgescência dos tecidos vegetais. Dias et al. (2011) relataram que a perda de massa em frutos de mamoeiro não tratados pode ser superior a $12 \%$ após 10 dias de armazenamento sob temperatura ambiente. A epiderme do mamão é muito delgada, o que propicia maior perda de umidade para o meio externo, devido à diferença de pressão de vapor entre o fruto e o ambiente.

Para a aparência dos frutos não houve interação entre as doses dos extratos vegetais e o período de armazenamento, só havendo efeito isolado das doses dos extratos vegetais e o período de armazenamento. A aparência diminuiu com o decorrer do tempo de armazenamento de 5 (excelente) para notas inferiores a 3 (regular), como mostra a Figuras-5. Quanto aos extratos vegetais, os frutos tratados com Momordica charantia, apresentaram maiores notas de aparência, principalmente na concentração de $10 \mu \mathrm{g} \cdot \mathrm{mL}^{-1}$, para o extrato de Allamanda blanchetti, não houve diferença entre os tratamentos (Figuras 5).

As diferentes concentrações dos extratos de A. blanchetti e M. charantia apresentaram notas de aparência menores que 3 , sendo essa nota o limite para comercialização, uma vez que considera-se que frutos com notas inferiores a 3 são imprestáveis para comercialização Rocha et al. (2005).

As modificações na coloração das frutas com a maturação ocorrem devido a processos degradativos, como a processos sintéticos. Elas correspondem a um dos principais critérios de julgamento para identificação do amadurecimento e ponto de consumo (Fagundes \& Yamanishi, 2001).

A antracnose é responsável por causar infecções e pode ocorrer aparecimento de manchas inicialmente vermelho-arroxeadas, evoluindo para manchas necróticas, reduzindo a qualidade dos frutos infectados Moura et al. (2013). Desta forma, a avaliação da aparência pode ser uma alternativa para comprovar até que ponto a presença da doença deprecia o valor de comercialização dos frutos. 

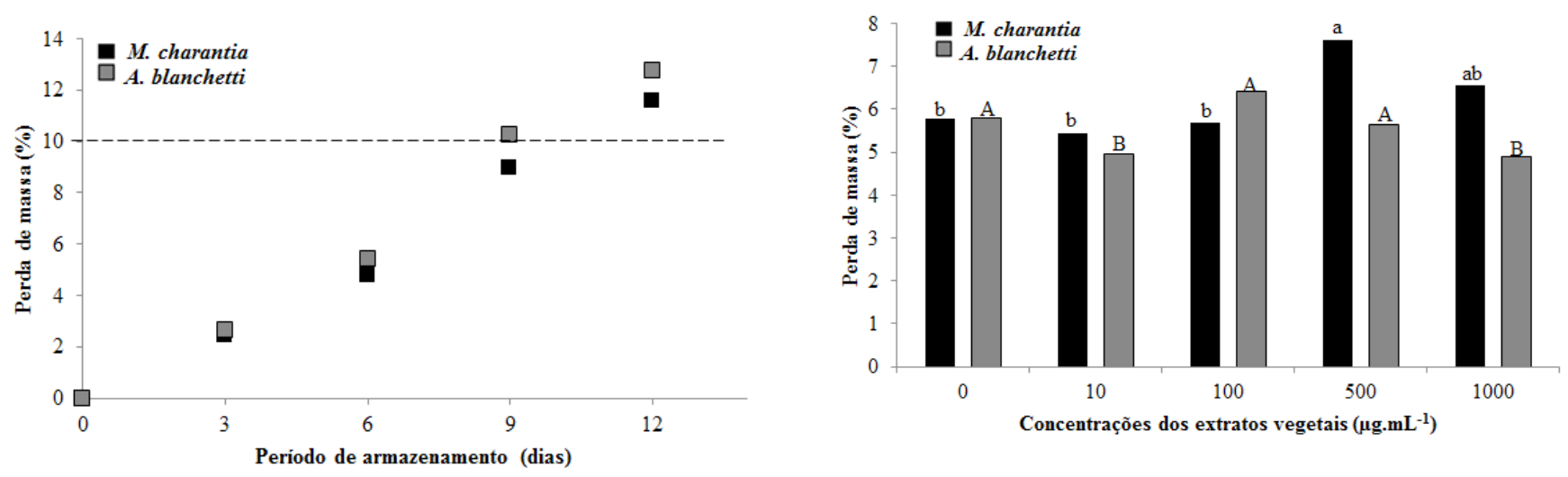

FIGURAS 4. Perda de massa (\%) em frutos de Carica papaya da cultivar Sunrise solo, tratados com diferentes concentrações dos extratos de Allamanda blanchetti e Momordica charantia durante 12 dias de armazenamento.
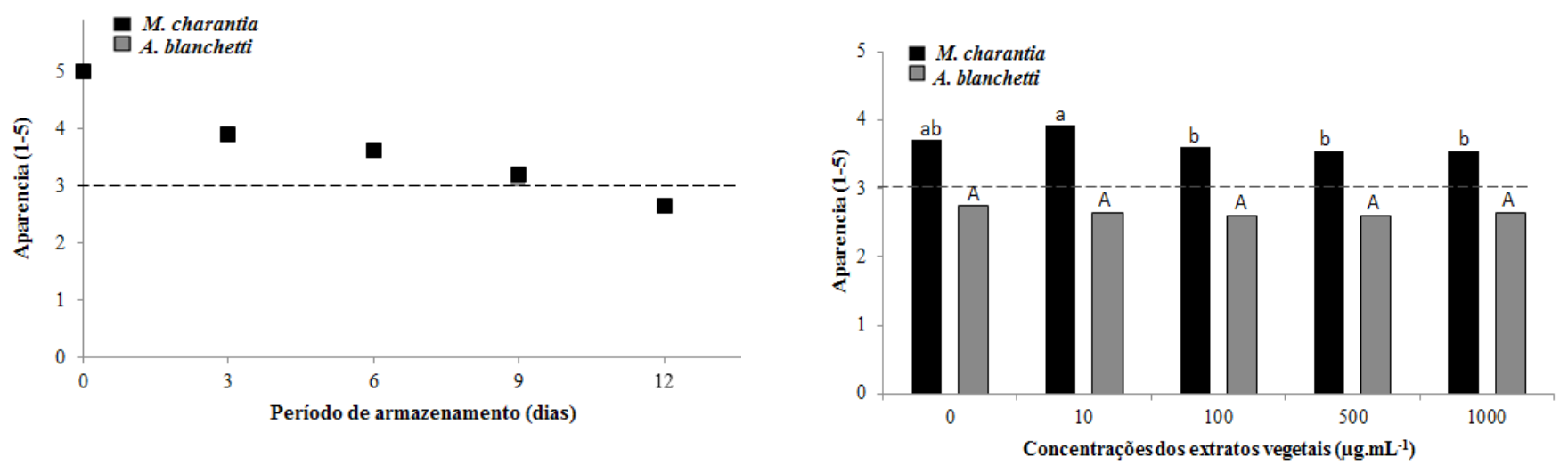

FIGURAS 5. Aparência (1-5) em frutos de Carica papaya da cultivar Sunrise solo tratados com diferentes concentrações dos extratos de Allamanda blanchetti e Momordica charantia durante 12 dias de armazenamento.

\section{CONCLUSÃO}

Os extratos de $A$. blanchetti e $M$. charantia não reduziram a incidência natural de $C$. gloesporioides em frutos de mamoeiro, porém, a severidade foi reduzida quando utilizou-se o extrato de $A$. blanchetti. Observou-se que a atividade da enzima peroxidase ocorreu em todos os extratos e concentrações utilizadas e conservaram a qualidade pós-colheita dos frutos até nove dias de armazenamento.

\section{REFERÊNCIAS}

AOAC: ASSOCIATION OF OFFICIAL ANALYTICAL CHEMISTRY. Washington, Official methods of analysis of the Association of Official Analytical Chemistry. 17ed. Washington: AOAC, 1995. 1115p.

ARNASON, J.T. et al. Inseticides of plant origin. Washington: The American Chemical Society, 1989. $213 p$.

BONETT, L.P. et al. Extrato etanólico de representantes de cinco famílias de plantas e óleo essencial da família Asteraceae sobre o fungo Colletotrichum gloeosporioides coletados de frutos de mamoeiro (Carica papaya L.). Revista Brasileira de Agroecologia, v.7, n.3, p.116-125, 2012.

CARNELOSSI, P.R. et al. Óleos essenciais no controle pós-colheita de Colletotrichum gloeosporioides em mamão. Revista Brasileira de Plantas Medicinais, v.11, n.4, p. 399-406, 2009.

CARRERA, G.C. et al. Testes fioquímicos em extratos foliares de Oeceoclades maculata Lindl. (Orchidaceae). Revista Brasileira de Plantas Medicinais, v.16, n.4, p.938-944, 2014.

CAVALCANTI, F.R. et al. Atividades de quitinase e beta1,3-glucanase após eliciação das defesas do tomateiro contra a mancha-bacteriana. Pesquisa Agropecuária Brasileira, v.41, p.1721-1730, 2006.

DIAS, T.C. et al. Conservação pós-colheita de mamão formosa com filme de PVC e refrigeração. Revista Brasileira de Fruticultura, v.33, n.2, p.666-670, 2011.

FAGUNDES, G.R.; YAMANISHI, O.K. Características físicas e químicas de frutos de mamoeiro do grupo 'Solo' comercializados em 4 estabelecimentos de Brasília-DF. Revista Brasileira de Fruticultura, v.23, n.3, p.541545, 2001.

GUIRADO, N. et al. Controle de doenças em sistemas agroecológico. Summa Phytopathologica, v.30, n.1, p.153-156, 2004.

HUAN, S.K.H. et al. Scutellaria baicalensis alleviates 
cantharidin-induced the morrhagic cystitis through inhibition of cyclo oxygenase-2 over expression. Molecules, v.17, p.6277-89, 2012.

IBGE- INSTITUTO BRASILEIRO DE GEOGRAFIA E ESTATÍSTICA- 2015. Produção nacional do mamoeiro. Disponível em: <www.ibge.gov.br.>. Acesso em: 17 de Mar. 2015.

IAL. Métodos físico-químicos para análise de alimentos. 4. ed. São Paulo: IAL, 1020p. 1. ed. digital. 2008.

LEITE, C.D. et al. Controle pós-Colheita da podridão amarga da maçã com o uso do óleo de nim. Resumos do VI CBA e II CLAA. Revista Brasileira de Agroecologia, v.4, n.2, p. 1644-1648, 2009.

LURIE, S. et al. The possible involvement of peroxidase in resistance to Botrytis cinerea in heattreated tomato fruit. Physiological and Molecular Plant Pathology, v.50, p.141-149, 1997.

MARTINS-RAMOS, D. et al. Plantas medicinais de um remascente de Floresta Ombrófila Mista Altomontana, Urupema, Santa Catarina, Brasil. Revista Brasileira de Plantas Medicinais, v.12, n.3, p.380-397, 2010.

MASCARENHAS, R.J. et al. Avaliação sensorial de uvas de mesa produzidas no Vale do São Francisco e comercializadas em João Pessoa-PB. Revista Brasileira de Fruticultura, v.32, n.4, p.993-1000, 2010.

MENEZES, M. Aspectos Biológicos e Taxonômicos de Espécies do Gênero Colletotrichum. Anais da Academia Pernambucana de Ciência Agronômica, v.3, p.170-179, 2006.

MOURA, F.T de et al. Frutos do umbuzeiro armazenados sob atmosfera modificada e ambiente em diferentes estádios de maturação. Revista Ciência Agronômica, v.44, n.4, 2013.

NERY-SILVA, F.A. et al. Controle químico da podridão peduncular de mamão causada por Colletotrichum gloeosporioides. Ciência Agrotécnica, v.25, p.519524, 2001.
PAIXÃO, M.V.S. et al. Frações orgânicas e mineral na produção de mudas de mamoeiro. Revista Brasileira Fruticultura, v.34, n.4, p.1105-1112, 2012.

ROCHA, R.H.C. et al. Qualidade pós-colheita do mamão Formosa armazenado sob refrigeração. Revista Brasileira de Fruticultura, v.27, n.3, p.386-389, 2005.

RONCATO, M.C.; PASHOLATI, S.F. Alterações na atividade e no perfil eletroforético da peroxidase em folhas de milho (Zea mays) e sorgo (Sorghum bicolor) tratadas com leveduras (Saccharomyces cerevisiae). Scientia Agricola, v.55, n.3, p.395-402, 1998.

SANGOI, L. et al. Incidência e severidade de doenças de quatro híbridos de milho cultivados com diferentes densidades de plantas. Ciência Rural, v.30, n.1, p.1721, 2000.

SANTANA, L.R.R. et al. Genótipos melhorados de mamão (Carica papaya L.): avaliação sensorial e físico-química dos frutos. Ciência e Tecnologia de Alimentos, v.24(2), p.217-222, 2004.

SERRANO, L. A.; CATTANEO, L. F. O cultivo do mamoeiro no Brasil. Revista Brasileira de Fruticultura, v.32, n.3, p.657-959, 2010.

SILVA, R.S da et al. Qualidade de uva 'Isabel' tratada com cloreto de cálcio em pós-colheita e armazenada sob atmosfera modificada. Revista Brasileira de Fruticultura, v.34, n.1, p.050-056, 2012.

SIQUEIRA-JUNIOR, C.L. et al. Controle de antracnose em mamão por extratos vegetais. Perspectivas online, v.1, n.1, p.99-105, 2011.

TAVARES, G.M. et al. Indução de resistência do mamoeiro à podridão radicular por indutores bióticos e abióticos. Pesquisa Agropecuária Brasileira, v.44, n.11, p.14161423, 2009.

WILLS, R.B.H.; WIDJANARKO, S.B. Changes in physiology, composition and sensory characteristics of Australian papaya during ripening. Australian Journal of Experimental Agriculture, n.35, p.11731176, 1995.

\section{ERRATA}

Na página 1041, onde se lia:

"NASCIMENTO, C.L.":

DEMARTELAERE, A.C.F.1; GUIMARÃES, G.H.C.1; SILVA, J.A.1; LUNA, R.G.'; NASCIMENTO, C.L. ${ }^{1}$

Leia-se:

“NASCIMENTO, L.C.":

DEMARTELAERE, A.C.F.. ${ }^{*} ;$ GUIMARÃES, G.H.C. ${ }^{1 ;}$ SILVA, J.A. ${ }^{1 ;}$ LUNA, R.G. ${ }^{1 ;}$ NASCIMENTO, L.C. ${ }^{1}$ 